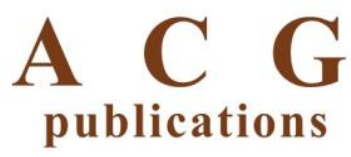

Rec. Nat. Prod. 13:5 (2019) 418-423

records of natural

products

\title{
A New Isoflavonolignan Glycoside from Abrus cantoniensis
}

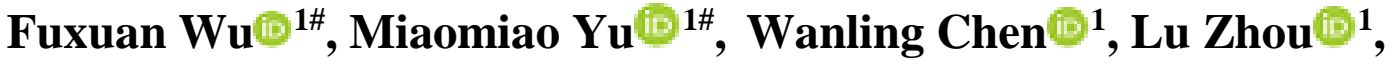 \\ Dan Zhang $\odot$, Yujie Peng $\odot$, Xifeng Sheng ${ }^{1}$, Hui Zou $\odot 1,2,3,{ }^{*}$ and \\ Junjiang Fu 2*
}

\author{
${ }^{1}$ Key Laboratory of Study and Discovery of Small Targeted Molecules of Hunan Province, School of \\ Medicine, Hunan Normal University, Changsha 410013, China \\ ${ }^{2}$ Key Laboratory of Epigenetics and Oncology, Research Center for Preclinical Medicine, Southwest \\ Medical University, Luzhou, Sichuan 646000, China \\ ${ }^{3}$ Key Laboratory of Chemical Biology \& Tranditional Chinese Medicine Research (Ministry of \\ Education of China) and Key Laboratory of Phytochemical R\&D of Hunan Province, Hunan Normal \\ University, Changsha 410081, Hunan, China
}

(Received January 23, 2019; Revised February 14, 2019; Accepted February 24, 2019)

\begin{abstract}
A new isoflavonolignan glycoside, namely cantoniensin A (1), along with three known compounds were isolated from Abrus cantoniensis. The structure of the new compound was elucidated on the basis of spectroscopic analyses, including 1D-, 2D-NMR and HRESIMS. Compound $\mathbf{1}$ is the second example of isoflavonolignan glycoside from nature and is also the first isoflavonolignan isolated from the genus of Abrus.
\end{abstract}

Keywords: Leguminosae; Abrus cantoniensis; cantoniensin A; isoflavonolignan; isoflavonolignan glycoside. (c) 2019 ACG Publications. All rights reserved.

\section{Introduction}

Abrus cantoniensis Hance (Jigucao in Chinese), a traditional plant of Leguminosae family in Southern China and some countries of Southeast Asia, was extensively used as an edible vegetable and medicinal plant. The whole plant can be used to make beverages or herbal tea alone or with other plant materials. In China, it is used as a folk medicine for treating acute and chronic hepatitis, jaundice, rheumatism and removing the liver toxicants [1-2]. In previous studies, A. cantoniensis was reportedly showed potential biological activities including antioxidant [2-4], anti-tumor [5-6], immunoregulatory activity [5] and wound healing activity [7]. Some chemical constituents have been isolated from $A$. cantoniensis, such as triterpenes, thraquinones, flavonoids, and alkaloids [8-11], while isoflavones have never been reported in this plant.

To search for the bioactive constituents, an investigation of secondary metabolites of this plant was carried out and resulted a new isoflavonolignan glycoside, cantoniensin A (1), along with three known compounds (2-4) including two isoflavones were isolated from A. cantoniensis. To the best of our knowledge, isoflavonolignans were seldom isolated as nature sources and only found in Leguminosae family at present. Compound 1 represents the second example of isoflavonolignan

\footnotetext{
\# These authors contributed equally to this work.

* Corresponding authors: Email: zouhui308@163.com (Hui Zou) and fujunjiang@ hotmail.com (Junjiang Fu)
} 
glycoside from nature and also the first isoflavonolignan isolated from the genus of Abrus. Herein, we describe the isolation and structural elucidation of these compounds.

\section{Materials and Methods}

\subsection{General}

Optical rotation was recorded on a WZZ-2S polarimeter. NMR spectra were recorded on a Bruker AV-500 MHz spectrometer with TMS as the internal standard. HRESIMS was recorded on an Agilent Technologies liquid chromatograph connected to a Q-TOF mass spectrometer. Silica gel (200300 mesh) and ODS-A (YMC-GEL) were used for open column chromatography (CC). TLC were conducted on silica gel GF254 plates to monitor the fractions. Sephadex LH-20 were used for column chromatography (CC). HPLC and Semi-preparative HPLC experiments were carried out using an Agilent 1100 HPLC system with a YMC ODS column $(250 \times 4.6 \mathrm{~mm}, 10 \mu \mathrm{m})$ and YiLiTe SinoChrom ODS-BP colunm $(250 \times 10 \mathrm{~mm}, 10 \mu \mathrm{m})$ respectively.

\subsection{Plant Material}

The air-dried whole herbs of A. cantoniensis were collected from Yulin of Guangxi Province, China in April 2017 and identified by Prof. Xi-Feng Sheng, Hunan normal university. A voucher specimen (No. JGC-2017) has been deposited in the Laboratory of Phytochemistry, School of Medicine, Hunan Normal University.

\subsection{Extraction and Isolation}

The air-dried plant of $A$. cantoniensis $(20 \mathrm{~kg})$ was extracted with $70 \% \mathrm{EtOH}$ under reflux, and then concentrated under reduced pressure to give a crude extract $(3 \mathrm{~L})$. The extract was suspended in $\mathrm{H}_{2} \mathrm{O}$, partitioned successively with $\mathrm{CH}_{2} \mathrm{Cl}_{2}$, EtOAc and $n-\mathrm{BuOH}$ to afford $\mathrm{CH}_{2} \mathrm{Cl}_{2}(137.5 \mathrm{~g})$, EtOAc $(82 \mathrm{~g}), n$-BuOH $(190 \mathrm{~g})$ soluble fractions. The EtOAc extract was subjected to a sephadex LH-20 column chromatography eluted with $\mathrm{MeOH}$ to provide 108 fractions which were analyzed by TLC and HPLC. Fr. 43 Fr.45 were further purified by preparative HPLC $\left(30 \%\right.$ ACN- $\left.\mathrm{H}_{2} \mathrm{O}\right)$ to obtain compounds 1 (13.0 mg). The $\mathrm{CH}_{2} \mathrm{Cl}_{2}$ portion was subjected to silica gel column eluted with $\mathrm{CH}_{2} \mathrm{Cl}_{2}-$ $\mathrm{MeOH}(98: 2,96: 4,94: 6,92: 8,9: 1,1: 1)$ afford fractions Fr. 1 Fr. 92. Fr. 5 was chromatographed on ODS-A column eluted with $\mathrm{MeOH}-\mathrm{H}_{2} \mathrm{O}(70 \%, 80 \%, 90 \%, 100 \%)$ to yield Fr. 5.5, which further purified by preparative HPLC ( $\left.38 \% \mathrm{ACN}-\mathrm{H}_{2} \mathrm{O}\right)$ to afford $2(7 \mathrm{mg}), 3(11 \mathrm{mg})$ and $4(6.5 \mathrm{mg})$.

\subsection{Spectroscopic Data}

Cantoniensin A (1): yellow amorphous powder. $[\alpha]_{D}^{20}=+12.0$ (c $\left.0.01, \mathrm{MeOH}\right) ;{ }^{1} \mathrm{H}-\mathrm{NMR}$ and ${ }^{13} \mathrm{C}-\mathrm{NMR}$ (DMSO- $d_{6}, 500 / 125 \mathrm{MHz}$ ) see Table 1; HRESIMS calcd. for $\mathrm{C}_{32} \mathrm{H}_{32} \mathrm{O}_{13} \mathrm{H}[\mathrm{M}+\mathrm{H}]^{+} \mathrm{m} / z$ 625.1921, found 625.1925.

\subsection{Acid Hydrolysis}

Compound $1(2 \mathrm{mg})$ was refluxed with $5 \% \mathrm{HCl}$ in $\mathrm{MeOH}(5 \mathrm{~mL})$ for 2 hours and then extracted with EtOAc $(10 \mathrm{~mL})$ for 3 times. The aqueous layer was neutralized with $\mathrm{NaHCO}_{3}$ and concentrated in vacumn to give a residue. The sugar unit in the aqueous layer was identified as D-glucose on the basis of TLC (BuOH-AcOH- $\mathrm{H}_{2} \mathrm{O}, 4: 1: 5$ upper layer)[12]. 


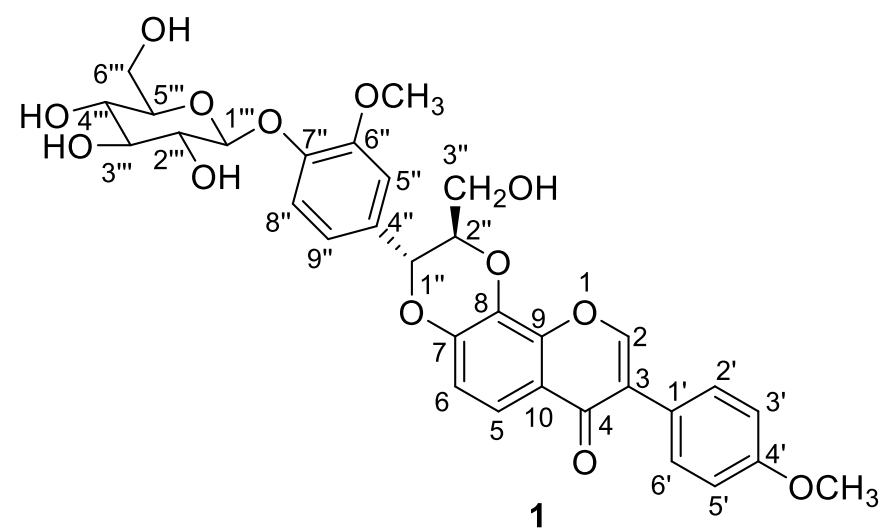<smiles>COc1ccc2c(c1)O[C@H]1c3ccc(O)cc3OC[C@H]21</smiles><smiles>COc1ccc(-c2coc3c(OC)c(O)ccc3c2=O)cc1</smiles>

3<smiles>COc1ccc(-c2coc3c(O)c(OC)ccc3c2=O)cc1</smiles>

4

Figure 1. Structures of compounds 1-4

\section{Results and Discussion}

\subsection{Structure Elucidation}

Compound 1 was obtained as a pale yellow amorphous powder. Its molecular formula was determined to be $\mathrm{C}_{32} \mathrm{H}_{32} \mathrm{O}_{13}$ with 17 degrees of unsaturation on the basis of the HRESIMS $(\mathrm{m} / \mathrm{z}$ 625.1925 $[M+\mathrm{H}]^{+}$, calcd. 625.1921) and the ${ }^{13} \mathrm{C}$ NMR data (Table 1).

The ${ }^{1} \mathrm{H}$ NMR spectrum of 1 displayed two ortho-coupling aromatic protons at $\delta_{\mathrm{H}} 7.63,7.11(1 \mathrm{H}$ each, $\mathrm{d}, 8.8 \mathrm{~Hz}$ ), which was also proved by COSY spectrum. The HMBC cross-peaks (Figure 2) from $\delta_{\mathrm{H}} 7.63(\mathrm{H}-5)$ to C-4, C-7 and C-9 and from $\delta_{\mathrm{H}} 7.11(\mathrm{H}-6)$ to $\mathrm{C}-7, \mathrm{C}-8$ and C-10 together with the COSY correlation of $\mathrm{H}-5 / \mathrm{H}-6$ indicated the assignment of these two protons at $\mathrm{C}-5$ and $\mathrm{C}-6$ respectively. The ${ }^{1} \mathrm{H}$ NMR spectrum showed para-substituted benzene signals at $\delta_{\mathrm{H}} 7.54(2 \mathrm{H}, \mathrm{d}, 8.7$ $\left.\mathrm{Hz}, \mathrm{H}-2^{\prime}, 6^{\prime}\right)$ and $7.01\left(2 \mathrm{H}, \mathrm{d}, 8.7 \mathrm{~Hz}, \mathrm{H}-3^{\prime}, 5^{\prime}\right)$, and a characteristic vinylic singlet at $\delta_{\mathrm{H}} 8.51(1 \mathrm{H}, \mathrm{s}$, $\mathrm{H}-2$ ) for isoflavone moiety which was observed in the HMBC spectrum to correlate with C-4, C-9 and $\mathrm{C}-1^{\prime}$. Besides, a methoxy group was observed at $\delta_{\mathrm{H}} 3.79\left(3 \mathrm{H}, \mathrm{s}, 4^{\prime}-\mathrm{OMe}\right)$ corresponding to the carbon signal at $\delta_{\mathrm{C}} 55.6$ in HMQC spectrum. The HMBC correlation from $\delta_{\mathrm{H}} 3.79\left(4^{\prime}-\mathrm{OMe}\right)$ to $\delta_{\mathrm{C}} 159.5$ demonstrated this methoxy group linked to $\mathrm{C}-4^{\prime}$. These above evidences revealed an isoflavone unit (7,8-dihydroxy-4'-methoxyisoflavone) in the structure of compound $\mathbf{1}$.

Further examination of NMR spectra revealed a phenylpropanoid unit in the structure of $\mathbf{1}$. The signals of $\delta_{\mathrm{H}} 7.14\left(1 \mathrm{H}\right.$, brs, $\left.\mathrm{H}-5^{\prime \prime}\right), 7.15\left(1 \mathrm{H}, \mathrm{d}, 8.7 \mathrm{~Hz}, \mathrm{H}-8^{\prime \prime}\right)$ and $7.01\left(1 \mathrm{H}, \mathrm{d}, 8.7 \mathrm{~Hz}, \mathrm{H}-9^{\prime \prime}\right)$ along with the COSY spectrum proposed a 1,3,4-trisubstituted phenyl ring of the phenylpropanoid unit. The deshielded doublet at $5.17\left(1 \mathrm{H}, \mathrm{d}, 7.8 \mathrm{~Hz}, \mathrm{H}-1^{\prime \prime}\right)$ is a typical oxygenated benzylic methine and this doublet was coupled with the multiplet at $\delta_{\mathrm{H}} 4.42(1 \mathrm{H}, \mathrm{m}, \mathrm{H}-2 ")$ in COSY spectrum. The signals at $3.68(1 \mathrm{H}, m)$ and $3.45(1 \mathrm{H}, m)$ was proved to be a hydroxymethyl at C-3" by HSQC and COSY spectra. The HMBC correlations from H-1" to C-4", 5" and C-9", from H-2" to C-4" and form H-3" to C-1" and C-2" confirmed that the phenylpropanoid unit is composed of a 1,2,3-tritrioxygenated side chain and a 1,3,4-trisubstituted phenyl ring. The HMBC correlations from $\delta_{\mathrm{H}} 3.79$ (6"-OMe), $7.15\left(\mathrm{H}-8^{\prime \prime}\right)$ to $\delta_{\mathrm{C}} 149.4\left(\mathrm{C}-6^{\prime \prime}\right)$ confirmed the other methoxy group ws located at C-4". Except the isoflavonol and phenylpropanoid units, the NMR spectra also showed an anomeric proton and an anomeric carbon at $\delta_{\mathrm{H}} 4.95$ and $\delta_{\mathrm{C}} 100.4$ respectively, which suggested the presence of a sugar moiety. The configuration of the glucosyl was confirmed as $\beta$-glucopyranose by the carbon signals at $\delta_{\mathrm{c}} 100.4,73.6,77.5,70.1$, 77.3 and 60.3 and the the coupling constant $(\mathrm{J}=8.7 \mathrm{~Hz})$ of the anomeric proton. And the glucosyl was 
identified as D-glucose by TLC analysis after hydrolysis [13]. The HMBC correlations from H-1"' to C-7" and NOESY correlation (Figure 3) between H-1"' and H-8" indicated the sugar moiety was connected with C-7". Except for 16 degrees of unsaturation of the above fragments, the structure of $\mathbf{1}$ still remains one degree of unsaturation. Together with the molecular formula, a 1,4-dioxane ring between the isoflavonoid moiety and the phenylpropanoid unit was deduced. The linkage of the isoflavonol and phenylpropanol units at C-1" and C-2" was confirmed by the long-range correlation from $\mathrm{H}-2$ " to C-8. The trans stereochemistry was determined by the coupling constant $(7.8 \mathrm{~Hz})$ between H-1" and H-2" and the NOE correlations between H-2" and H-5", H-9", and NOE correlation between $\mathrm{H}-1$ " and $\mathrm{H}-3$ " [14-15].

Therefore, compound $\mathbf{1}$ was elucidated as butesuperin A-7"-O- $\beta$-glucopyranoside and named cantoniensin A (Figure 1). To best of our knowledge, there were very few isoflavonolignans reported as natural sources and only isolated in the family Leguminosae.

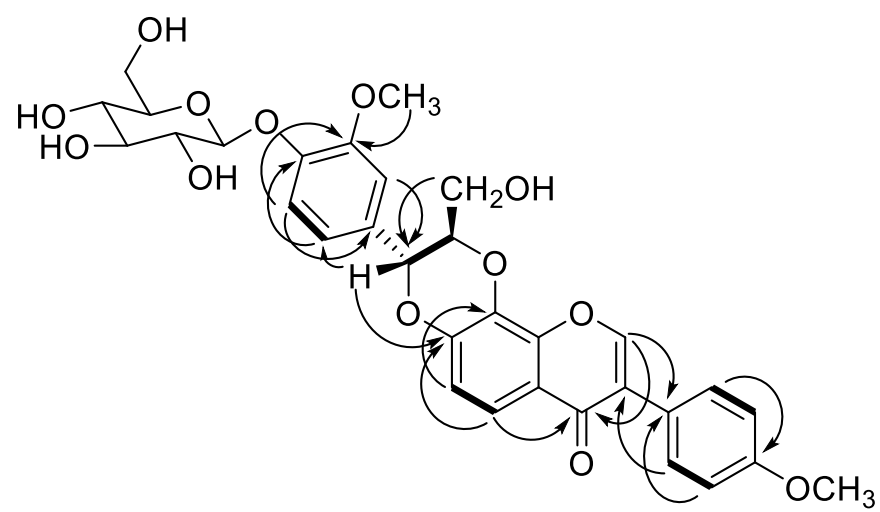

Figure 2. Key ${ }^{1} \mathrm{H}-{ }^{1} \mathrm{H}$ COSY and $\mathrm{HMBC}$ correlations of compound $\mathbf{1}$

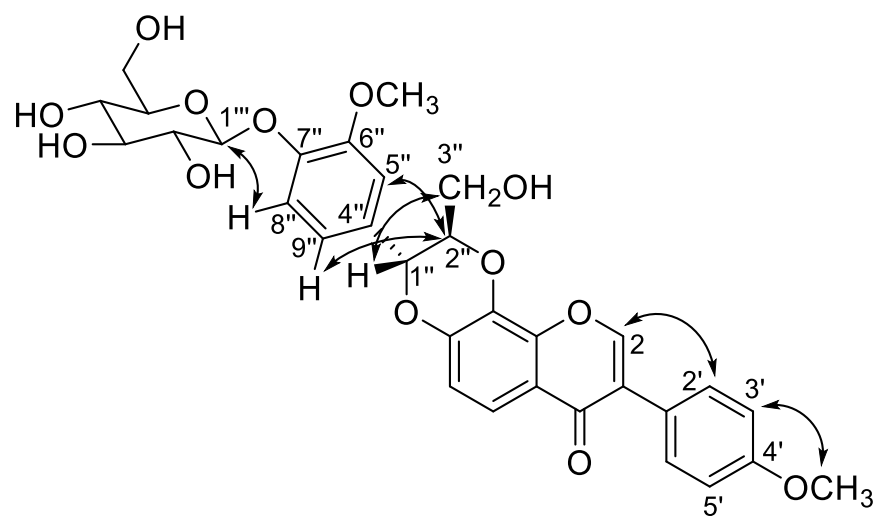

Figure 3. Key NOESY correlations of compound 1

The three known compounds were identified as medicarpin (2) [16], 8-O-methylretusin (3) [17] and 8-hydroxy-4',7-dimethoxyisoflavone (4) [18] by comparing their spectroscopic data with those reported in the literatures. These three compounds were firstly isolated from the genus of Abrus. 
Table 1. ${ }^{1} \mathrm{H}$ NMR $(500 \mathrm{MHz})$ and ${ }^{13} \mathrm{C}$ NMR $(125 \mathrm{MHz})$ data for compound 1 in DMSO- $d_{6}$

\begin{tabular}{lll}
\hline Position & $\delta_{\mathrm{H}}(\mathrm{ppm}) J(\mathrm{~Hz})$ & $\delta_{\mathrm{C}}(\mathrm{ppm})$ \\
\hline 2 & $8.51(1 \mathrm{H}, s)$ & 153.6 \\
3 & & 124.4 \\
4 & & 175.1 \\
5 & $7.63(1 \mathrm{H}, d, J=8.8)$ & 117.2 \\
6 & $7.11(1 \mathrm{H}, d, J=8.8)$ & 115.5 \\
7 & & 147.7 \\
8 & & 132.3 \\
9 & & 146.4 \\
10 & & 118.9 \\
$1^{\prime}$ & & 123.7 \\
$2^{\prime} / 6^{\prime}$ & $7.54(2 \mathrm{H}, d, J=8.7)$ & 130.6 \\
$3^{\prime} / 5^{\prime}$ & $7.01(2 \mathrm{H}, d, J=8.7)$ & 114.1 \\
$4^{\prime}$ & & 159.5 \\
$4^{\prime}-\mathrm{OCH}$ & 55.6 \\
$1^{\prime \prime}$ & $3.79(3 \mathrm{H}, s)$ & 76.6 \\
$2^{\prime \prime}$ & $5.17(1 \mathrm{H}, d, J=7.8)$ & 78.5 \\
$3^{\prime \prime}$ & $4.42(2 \mathrm{H}, m)$ & 61.1 \\
& $3.45(1 \mathrm{H}, m)$ & \\
$4^{\prime \prime}$ & $3.68(1 \mathrm{H}, m)$ & 129.8 \\
$5^{\prime \prime}$ & & 112.6 \\
$6^{\prime \prime}$ & $7.14(1 \mathrm{H}, b r s)$ & 149.4 \\
$7^{\prime \prime}$ & & 147.5 \\
$8^{\prime \prime}$ & & 115.4 \\
$9^{\prime \prime}$ & $7.15(1 \mathrm{H}, d, J=8.7)$ & 120.8 \\
$6^{\prime \prime}-\mathrm{OCH}$ & 56.3 \\
Glc & $7.01(1 \mathrm{H}, d, J=8.7)$ & \\
$1^{\prime \prime \prime}$ & $3.79(3 \mathrm{H}, s)$ & 100.4 \\
$2^{\prime \prime \prime}$ & & 73.6 \\
$3^{\prime \prime \prime}$ & & 77.5 \\
$4^{\prime \prime \prime}$ & $3.95(1 \mathrm{H}, d, J=8.7)$ & 70.1 \\
$5^{\prime \prime \prime}$ & $3.27(1 \mathrm{H}, m)$ & 77.3 \\
$6^{\prime \prime \prime}$ & $3.30(1 \mathrm{H}, m)$ & 60.3 \\
\hline
\end{tabular}

\section{Acknowledgments}

This work was partially supported by the National Natural Science Foundation of China (31400311 and 81672887), Natural Science Foundation of Hunan province (2017JJ3213 and 2018JJ2268), Opening Fund of Key Laboratory of Chemical Biology and Traditional Chinese Medicine Research (Hunan Normal University), Ministry of Education (KLCBTCMR18-06) and the Joint Research Fund of QiLu Pharmacuetical Co. Ltd.

\section{Supporting Information}

Supporting information accompanies this paper on http://www.acgpubs.org/journal/recordsofnatural-products

\section{ORCID}

Fuxuan Wu: 0000-0001-5979-2418

Miaomiao Yu: $0000-0001-7421-4210$

Wanling Chen: 0000-0003-3675-8991

Lu Zhou: 0000-0003-0578-760X

Dan Zhang: 0000-0001-8004-3817

Yujie Peng: 0000-0002-9822-6694 
Xifeng Sheng: 0000-0002-2899-994X

Hui Zou: 0000-0003-4594-6302

Junjiang Fu: $\underline{0000-0002-0708-2200}$

\section{References}

[1] Z. Wei (1994). Flora of China, vol. 40, Science Press, Beijing, China.

[2] M. Yang, Q. Shen, L. Q. Li, Y. Q. Huang and H.Y. Cheung (2015). Phytochemical profiles, antioxidant activities of functional herb Abrus cantoniensis and Abrus mollis, Food Chem. 177, 304-312.

[3] H. Li, Z. J. Song, Y. P. Dai, S. L. Zhang, X. He, C. R. Guo, W. J. Zhang, J. Y. Wang, C. F. Zhang, C. Z. Wang and C. S. Yuan (2015). Antioxidative activity of flavonoids from Abrus cantoniensis against ethanolinduced gastric ulcer in mice, Planta Med. 8, 784-790.

[4] M. Yang, M. Al Zaharna, Y. S. Chen, L. Li and H.Y. Cheung (2014). In vitro antioxidant activities and antiproliferative properties of the functional herb Abrus cantoniensis and its main alkaloid abrine, Food. Funct. 5, 2268-2277.

[5] S. Wu, X. Fu, L. You, A. M. Abbasi, H. Meng, D. Liu and R. M. Aadil (2016). Antioxidant, antitumor and immunomodulatory activities of water-soluble polysaccharides in Abrus cantoniensis, Int. J. Biol. Macromol. 89, 707-716.

[6] S. Wu, X. Fu, L. You, M. A. Brennan, C. S. Brennan and C. Chun (2016). The effects of different purifying methods on the chemical properties, in vitro anti-tumor and immunomodulatory activities of Abrus cantoniensis polysaccharide fractions, Int. J. Mol. Sci. 17, 511 (16 pages).

[7] Q. Zeng, H. Xie, H. J. Song, F. Y. Nie, J. H. Wang and D. Chen (2016). In vivo wound healing activity of Abrus cantoniensis extract, Evid-based Compl. Alt. 2016, 6568528.

[8] H. Miyao, Y. Sakai, T. Takeshita, J. Kinjo and T. Nohara (1996).Triterpene saponins from Abrus cantoniensis (Leguminosae). I. Isolation and characterization of four new saponins and a new sapogenol, Chem. Pharm. Bull. 44, 1222-1227.

[9] H. Miyao, Y. Sakai, T. Takeshita, Y. Ito, J. Kinjo and T. Nohara (1996). Triterpene saponins from Abrus cantoniensis (Leguminosae). II. Characterization of six new saponins having a branched chain sugar, Chem. Pharm. Bull. 44, 1228-1231.

[10] S. M. Wong, T. C. Chiang and H. M. Chang (1982).Hydroxyanthraquinones from Abrus cantoniensis, Planta Med. 46, 191-192.

[11] H. M. Shi, J. Wen and P. F. Tu (2006). Chemical constituents of Abrus cantoniensis, Chin. Trad. Herb. Drugs 37, 1610-1613.

[12] F. Q. Xu, H. P. Hu, Y. Li, Y. S. Ren, H. S. Zhao, Q. Huang and J. T. Wang (2018). A New ent-pimarane-type diterpenoid glycoside from Siegesbeckia pubescens, Rec. Nat. Prod. 12, 493-497.

[13] H. S. Wang, L. Sun, Y. H. Wang, Y. N. Shi, G. H. Tang, F. W. Zhao, H. M. Niu, C. L. Long and L. Li (2011). Carboxymethyl flavonoids and a monoterpene glucoside from Selaginella moellendorffii, Arch. Pharm. Res. 34, 1283-1288.

[14] K. Ma, T. Ishikawa, H. Seki, K. Furihata, H. Ueki, S. Narimatsu, Y. Narimatsu and C. Chaichantipayuth (2005). Isolation of new isoflavonolignans, butesuperins A and B, from a Thai miracle herb, Butea superba, Heterocycles, 65, 893-900.

[15] D. S. Jang, E. J. Park, M. E. Hawthorne, J. S. Vigo, J. G. Graham, F. Cabieses, B. D. Santarsiero, A. D. Mesecar, H. H. Fong, R. G. Mehta, J. M. Pezzuto and A. D. Kinghorn. (2003). Potential cancer chemopreventive constituents of the seeds of Dipteryx odorata (tonka bean), J. Nat. Prod. 66, 583-587.

[16] I. Kitagawa, W. Z. Chen, K. Hori, E. Harada, N. Yasuda, M. Yoshikawa and J. Ren (1994). Chemical studies of Chinese licorice-roots. I. Elucidation of five new flavonoid constituents from the roots of Glycyrrhiza glabra L. collected in Xinjiang, Chem. Pharm. Bull. 42, 1056-1062.

[17] Y. Shirataki, S. Matsuoka, M. Komatsu, M. Ohyama, T. Tanaka and M. Iinuma (1999). Four isoflavanones from roots of Sophora tetraptera, Phytochemistry 51, 695-701.

[18] H. Goto, Y. Terao and S. Aka (2009). Synthesis of various kinds of isoflavones, isoflavanes, and biphenylketones and their 1,1-Diphenyl-2-picrylhydrazyl radical-scavenging activities, Chem. Pharm. Bull. 57, 346360 .

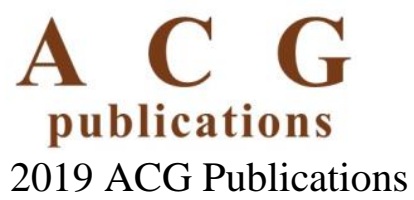

